\title{
Comparação entre os resultados da urinálise e dosagens bioquímicas urinárias de amostras de urina coletadas pelas técnicas de cistocentese guiada por ultrassom e sondagem uretral em cães*
}

\section{Comparison between the results of urinalysis and urinary biochemical tests of urine samples collected by techniques ultrasound-guided cystocentesis and urethral catheterization in dogs}

\author{
Kamila Teixeira Pandolfi, ${ }^{* *}$ Larissa Marchiori Sena, ${ }^{* *}$ Ronaldo Eugênio de Oliveira, ${ }^{* *}$ Silas Garcia Giori, ${ }^{* *}$ \\ Lenir Cardoso Porfírio,** Graziela Barioni**
}

\begin{abstract}
Resumo
Objetivou-se no presente estudo comparar as técnicas de coleta de urina via sondagem uretral e cistocentese guiada por ultrassom, afim de verificar se o método de coleta pode influir nos resultados laboratoriais. Foram utilizados 12 cães machos, sem histórico de enfermidades, dos quais coletou-se cinco mililitros $(\mathrm{mL})$ de urina via sondagem uretral e cinco $\mathrm{mL}$ via cistocentese guiada por ultrassom, ambas no mesmo momento. Posteriormente foi realizada a análise física (cor, odor, densidade, turbidez), química (urobilinogênio, glicose, corpos cetônicos, bilirrubina, proteína, nitrito, pH, sangue e leucócitos) e sedimentoscopia (avaliação de 10 campos de luz, objetiva de 40x). Cilindros urinários, cristais, corpúsculos gordurosos, espermatozoides, bactérias e células vesicais foram classificados qualitativamente como: ausentes (0), discretos (1), moderados (2) e intensos (3). Hemácias, leucócitos, e células de descamação foram quantificadas a partir da média dos campos analisados. As análises bioquímicas de microalbuminúria, creatinina e proteína total urinárias foram realizadas a partir do sobrenadante urinário, removido das amostras após centrifugação, e utilizados kits reagentes, conforme recomendação do fabricante, sendo a leitura em espectrofotômetro. Em todos os testes realizados os valores de $p$ encontrados foram superiores 0,05 ( $p>0,05)$, excluindo-se a possibilidade de haver diferenças significativas dos resultados laboratoriais obtidos pelas duas formas de coleta.
\end{abstract}

Palavras-chave: cateterismo, microalbuminúria, proteinúria.

\begin{abstract}
The objective of this study was to compare two techniques of urine collection, urethral catheterization and ultrasound-guided cystocentesis, in order to verify if the collection method may influence the laboratory results. Twelve male dogs were used, with no history of diseases, of which five milliliters $(\mathrm{mL})$ of urine were collected by urethral catheterization and five $\mathrm{mL}$ by both at the same time. Subsequently, the samples underwent physical analysis (color, smell, density andturbidity), chemical analysis (urobilinogen, glucose, ketone bodies, bilirubin, protein, nitrite, $\mathrm{pH}$, blood and leukocytes) and sedimentoscopy (evaluation of 10 light fields, 40x objective). Urinary casts, fatty corpuscles, spermatozoa, bacteria and bladder epithelial cells were classified qualitatively as absent (0), discrete (1), moderate (2) and intense (3). Red blood cells, leukocytes and desquamation cells were quantified from the mean of the analyzed fields. The urine supernatants were obtained after centrifugation and were used for biochemical analyzes of microalbuminuria, urinary protein and creatinine. The reagent kits were used as recommended by the manufacturer and the samples were read by spectrophotometry. All tests presented $p$ values higher than 0,05 ( $p>0,05)$, excluding the possibility of significant differences between the laboratory results of both forms of urine collection.
\end{abstract}

Keywords: catheterization, microalbuminuria, proteinuria.

\section{Introdução}

As doenças do sistema urinário estão entre as enfermidades que mais acometem cães e gatos. Apresentam sintomatologia bastante inespecífica, sendo este um entrave para a realização do diagnóstico precoce (WAKI et al., 2010). Exames laboratoriais como urinálise, dosagem de microalbuminúria e a relação proteína urinária e creatinina urinária (RPC) deveriam ser solicitados rotineiramente devido a importância da identificação inicial das doenças do sistema urinário (MARYNISSEN et al.,

*Recebido em 6 de setembro de 2020 e aceito em 15 de julho de 2021.

**Universidade Federal do Espírito Santo, Centro de Ciências Agrárias e Engenharias, Departamento de Medicina Veterinária, Alegre, Espírito Santo, Brasil.

Autora para correspondência: Larissa Marchiori Sena - Imsmvet@gmail.com 
2017). A partir da urinálise, é possível avaliar a existência de cristais, doenças inflamatórias, infecciosas e/ou degenerativas que acometem o trato urinário (CHEW et al., 2012).

A microalbuminúrica é determinada pela presença de albumina na urina em quantidades superiores aos valores normais, porém, em concentrações inferiores aos limites de detecção de tiras reagentes. Dessa forma, é indicada como diagnóstico inicial de doença glomerular (WHITTEMORE et al., 2007). Segundo a International Renal Interest Society (IRIS) (2016) a RPC é um método de detecção de proteinúria precoce, e a partir de seus resultados é possível avaliar a progressão da doença renal. No entanto, alterações nas dosagens de microalbuminúria são prévias às alterações de RPC (CHEW et al., 2012). Existem vertentes afirmando, que o método de coleta influência nos resultados laboratoriais, induzindo a erros diagnósticos. Segundo a IRIS (2013a), a cistocentese é considerada como padrão ouro para a realização da RPC, cultura da urina e bioquímicos urinários.

A fim de avaliar se o método de coleta interfere nas dosagens bioquímicas urinárias, foram realizados estudos, comparando a coleta via cistocentese com a coleta via compressão manual em cães (BEATRICE et al., 2010) e gatos (VILHENA, 2015). Esses estudos comprovaram que em ambas as formas, a valor da RPC não se alterou. No entanto a comparação entre a cistocentese e a sondagem foi pouco abordada, provavelmente devido a técnica de sondagem carrear mais contaminantes e ser de difícil realização em comparação com a micção espontânea (IRIS, 2013b).

Porém, vale ressaltar que a sondagem é a técnica utilizada pelos veterinários, quando se trata de animais machos, o que reforça a importância da sua avaliação (RIZZI et al., 2017). Dessa forma, objetivou-se avaliar a influência da técnica de coleta urinária, via sondagem uretral e cistocentese guiada por ultrassom, nos resultados da urinálise e dosagens bioquímicas urinárias em cães machos.

\section{Materiais e métodos}

Esse projeto foi aprovado pela Comissão de Ética no Uso de Animais (CEUA) da Universidade Federal do Espírito Santo sob o número 046/2015. Foram coletadas urinas de 12 cães machos, hígidos, não castrados, de diferentes raças, portes e faixas etárias, atendidos no Hospital Veterinário da Universidade Federal do Espírito Santo, no período de agosto a dezembro de 2017, para realização de consultas de rotina ou avaliação pré-cirúrgica.

Os critérios de inclusão dos animais foram fundamentados na anamnese, exame físico e nos valores de ureia e creatinina séricos dentro dos parâmetros normais de acordo com Kaneko et al. (1997). Os tutores dos animais assinaram o Termo de Consentimento Livre e Esclarecido, antes dos procedimentos para que pudessem participar do presente estudo e assim autorizaram a realização da coleta dos materiais biológicos necessários.

A cistocentese precedeu a sondagem uretral a fim de eliminar os possíveis contaminantes que a sondagem poderia carrear a bexiga, e consequentemente contaminar a amostra de urina a ser colhida posteriormente por sondagem uretral.
Foram coletadas amostras por cistocentese e sondagem em todos os animais do estudo (12 cães) obtendo-se 24 amostras de urina para a realização do experimento.

Para realização da cistocentese, os animais foram mantidos em decúbito dorsal, o pênis foi desviado lateralmente da linha média com a mão não dominante do ultrassonografista para facilitar a localização e a punção da bexiga de forma guiada. Após a identificação da mesma, o local da punção foi higienizado com álcool 70\% (FOSSUM, 2014).

A identificação da bexiga foi realizada via ultrassom portátil (Titan ${ }^{\circledR}$ Sonosite, , Bothell, USA) equipado com transdutor convexo de 2,0 a 5,0 MHz). O mandril do cateter $n^{\circ} 20$, foi acoplado a seringa de cinco $\mathrm{mL}$, e então inserido no ângulo de $90^{\circ}$ em relação a pele do animal, rente ao transdutor do ultrassom. Foi então realizada a punção vesical de cinco $\mathrm{mL}$ de urina (FOSSUM, 2014).

A sondagem uretral foi realizada posterior a cistocentese. No animal em decúbito dorsal ou em estação, foi realizada a exposição do pênis, o mesmo foi higienizado com solução fisiológica a 0,9\%. Posteriormente realizou-se a passagem da sonda uretral calibre quatro, seis ou oito, variando com o tamanho do animal, via uretral até a bexiga. Uma seringa estéril foi então acoplada a sonda e realizada a coleta de cinco $\mathrm{mL}$ de urina (RIZZI et al., 2017). Em nenhuma das técnicas foi utilizado protocolo sedativo.

Todas as amostras de urina foram processadas e analisadas em até uma hora após a coleta sendo mantidas a temperatura ambiente. Análises físicas, químicas e sedimentoscopia das amostras de urina coletadas foram realizadas de acordo com o preconizado por Thrall et al. (2015).

No exame físico da urina avaliou-se cor, odor, aspecto e densidade urinária, que foi obtida pela técnica de refratometria (Modelo RHC-200ATC, Megabrix $®$, China). A análise química foi obtida com o uso de fitas de urinálise (UriGold Analisa®, Belo Horizonte, MG, Brasil), para avaliação dos seguintes parâmetros: urobilinogênio, glicose, corpos cetônicos, bilirrubina, proteína, nitrito, $\mathrm{pH}$, sangue e leucócitos.

Para análise do sobrenadante, a urina foi centrifugada ( LS-3 Plus $^{\circledR}$, Celm, Barueri, SP, país) a 1500 giros por minuto (gpm) durante cinco minutos, foi removido o sobrenadante, mantendo um $\mathrm{mL}$ de sedimento no tubo. Após homogeneização do sedimento, transferiu-se 20 microlitros $(\mu \mathrm{L})$ para lâmina de microscopia (26x76 milímetros $(\mathrm{mm}))$ e lamínula $(22 \times 22 \mathrm{~mm})$, e em microscópio óptico binocular $\left(\mathrm{CX} 41^{\circledR}\right.$, Olympus, Tóquio, Japão) em aumento de 400x, sendo avaliados 10 campos de luz.

Cilindros urinários, cristais, corpúsculos gordurosos, espermatozoides, bactérias e células de transição foram observados ora individualizados ora em grupamentos. Dessa forma, a avaliação média dos dez campos foi utilizada para classificação qualitativa desses analitos. Sendo classificados como: ausentes (0), discretos (1), moderados (2) e intensos (3).

Hemácias, leucócitos, e células de descamação não foram observados em agregados, dessa maneira, a quantificação foi realizada a partir da média dos 10 campos analisados.

O equipamento utilizado para as análises bioquímicas do sobrenadante urinário foi o espectrofotômetro (Biospectro, modelo SP-22, São Paulo, SP, Brasil ). Todos os procedimentos 
utilizados para a determinação das concentrações bioquímicas foram realizados de acordo com o fabricante.

Para a mensuração das concentrações de creatinina e proteína urinárias foram utilizados os kits (Vida Biotecnologia ${ }^{\circledR}$, Belo Horizonte, Mg Brasil ). A obtenção das concentrações de microalbuminúria foi feita através do kit para determinação da microalbuminúria- (Microalbuminúria-pp ${ }^{\star}$, GoldAnalisa Diagnóstica e LTDA, Belo Horizonte, Brasil).

A RPC foi obtida pela divisão da proteína urinária (UPt) pela creatinina urinária (UCr) (fórmula abaixo). Resultados superiores a 0,5 classificam os animais como proteinúricos (IRIS, 2016).

$$
\left(\frac{\mathrm{UPt}}{\mathrm{UCr}}=\mathrm{RPC}\right)
$$

A análise estatística foi realizada utilizando o software GraphPad Prism ${ }^{\circledR}$ versão 15 . O teste de normalidade de Shapiro-Wilk foi utilizado para determinar se cada parâmetro assume a distribuição normal ou não. Os testes de T de Student ou Mann Whitney investigaram a diferença entre os métodos em parâmetros que assumem e não assumem a distribuição normal, respectivamente. Com nível de significância de 95\% $(p<0,05)$.

Os parâmetros que seguiram a distribuição normal foram: $\mathrm{pH}$, células de descamação, hemácias, leucócitos, proteína (tira urinária), RPC, microalbuminúria proteína e creatinina urinária. E os parâmetros avaliados que não seguiram a distribuição normal foram: flora bacteriana, cilindros (hialinos, epiteliais, granulosos), cristais (bilirrubina, estruvita, fosfato amorfo e oxalato de cálcio), corpúsculos gordurosos, células vesicais e espermatozoides.

\section{Resultados e discussões}

É importante ressaltar que a análise do sedimento urinário foi realizada em todas as amostras de urina coletadas, e nenhum dos animais apresentou sedimento urinário indicando inflamação ativa. Os leucócitos das amostras obtidas por ambas as formas de coleta (figura 1) se mantiveram dentro dos parâmetros de referência como aceitável (menor que três leucócitos/campo) em amostras coletadas por cistocentese e (menor que sete leucócitos/campo) em amostras obtidas por sondagem (THRALL et al., 2015).

Pela técnica de sondagem uretral, 41,66\% (5/12) apresentaram bacteriúria na sedimentoscopia. $\mathrm{Na}$ avaliação das amostras coletadas via cistocentese guiada por ultrassson, 50,00\% (6/12) apresentaram bacteriúria. No entanto, não foram constatadas diferenças entre os métodos de coleta para a variável presença de bactérias $(p>0,05)$ (tabela 1), entre as técnicas avaliadas.

A presença de bactérias de forma isolada sem sinais de inflamação em ambos os métodos de coleta, é inadequada para o diagnóstico de infecção do trato urinário. Pois, problemas relacionados a contaminação externa, contaminação durante a coleta e após a coleta (no momento de transferência da amostra para recipientes de laboratório) entre outros fatores, podem resultar em um falso positivo das amostras em questão, como descrito por Weese et al. (2011).
Entretanto, IRIS (2013b) afirma que a cistocentese é tida como padrão ouro para coleta de material destinado a cultura bacteriana, pois teoricamente seria uma amostra sem a presença de agentes contaminantes presentes nas outras formas de coleta.

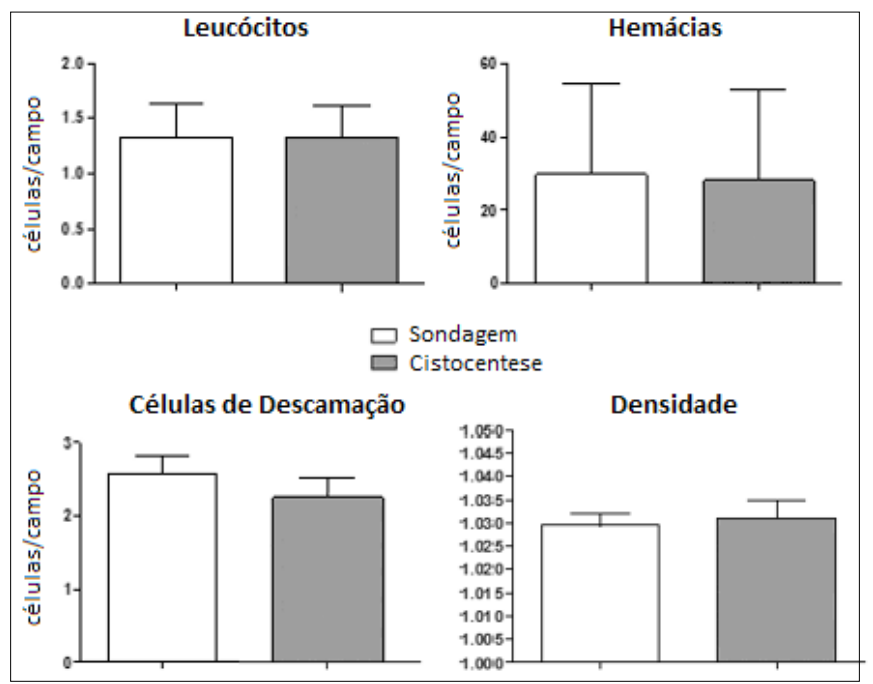

Figura 1: Demonstração gráfica dos valores médios e desvios padrão das variáveis, leucócitos, hemácias, células de descamação obtidos pela avaliação da sedimentoscopia (análise de 10 campos, aumento de 400x) e densidade urinária realizada por meio da refratometria nas amostras de cães machos inteiros por cistocentese e sondagem uretral. Sendo o valor de $p$ respectivamente: $p=1,00, p=0,96, p=0,36$, e $p=0,72$.

Tabela 1: Resultados estatísticos das variáveis não paramétricas qualitativas: cilindros (hialino, epitelial, granuloso), cristais de bilirrubina (CB), estruvita (CE), fosfato amorfo (CFA), oxalato de cálcio (COC), corpúsculos gordurosos (CG), espermatozoides, células vesicais e flora bacteriana nas amostras obtidas por cistocentese e por sondagem uretral

\begin{tabular}{cccc}
\hline Parâmetros & $\begin{array}{c}\text { Sondagem } \\
\text { (Mediana; } \\
\text { Erro padrão) }\end{array}$ & $\begin{array}{c}\text { Cistocentese } \\
\text { (Mediana; } \\
\text { Erro padrão) }\end{array}$ & Valor de $p$ \\
\hline Cilindro Hialino & 0,$00 ; 0,49$ & 0,$00 ; 0,45$ & 0,69 \\
Cilindro Epitelial & 0,$00 ; 0,29$ & 0,$00 ; 0,00$ & 1,00 \\
Cilindros Granulosos & 0,$00 ; 0,49$ & 0,$00 ; 0,49$ & 1,00 \\
CB & 0,$00 ; 0,39$ & 0,$00 ; 0,39$ & 0,96 \\
CE & 0,$00 ; 0,49$ & 0,$00 ; 0,51$ & 0,70 \\
CFA & 0,$00 ; 0,29$ & 0,$00 ; 0,29$ & 0,95 \\
COC & 0,$00 ; 0,00$ & 0,$00 ; 0,29$ & 1,00 \\
CG & 0,$00 ; 0,39$ & 0,$00 ; 0,45$ & 0,76 \\
Espermatozoides & 0,$00 ; 0,45$ & 0,$00 ; 0,45$ & 0,97 \\
Células vesicais & 0,$50 ; 0,52$ & 0,$00 ; 0,51$ & 0,65 \\
Flora bacteriana & 0,$00 ; 0,51$ & 0,$00 ; 0,49$ & 0,70 \\
\hline
\end{tabular}

Hematúria esteve presente em 50\% (6/12) das amostras coletas por sondagem uretral. Já nas amostras coletadas por 
cistocentese o aumento de hemácias foi observado em $41,66 \%$ (5/12). Os resultados obtidos na avaliação das hemácias no sedimento urinário estão dispostos na figura 1.

A presença de um indivíduo a mais contendo hemácias na amostra coletada por sondagem uretral provavelmente aconteceu devido a algum tipo de lesão ocasionado pela técnica de sondagem, e/ou lesão existente no trato urinário inferior. Entretanto, de acordo com. Forrester (2004) a técnica de cistocentese bem como o cateterismo, pode apresentar amostras contaminadas por hemácias. Isso ocorre por ser uma técnica invasiva, em que a urina é coletada por material perfurante.

Também, era esperada maior presença de células de descamação na coleta via sondagem uretral em comparação com a cistocentese, pois, a técnica de sondagem esfolia a uretra durante a colocação da sonda, podendo obter maior quantidade de material de descamação. Entretanto, a perfuração da pele durante a coleta via cistocentese explicaria a contaminação por células epiteliais de descamação nesse método de coleta (VAP; SHROPSHIRE, 2017). Assim, não havendo diferença estatística na avaliação deste parâmetro ( $p>0,05)$ (figura 1 ).

A maior presença de material descamativo nas amostras de urina coletadas por sondagem uretral, também seria capaz de influenciar o aumento da densidade urinária nas amostras coletadas por essa técnica, no entanto não foram observados dados correspondentes neste estudo (figura 1).

Outras causas de aumento da densidade urinária seriam cilindrúria, cristalúria, hematúria e proteinúria. $\mathrm{Na}$ urina de pacientes hígidos, a presença de raros a discretos cilindros hialinos e granulosos não caracteriza relevância clínica (RIZZI et al., 2017), como observado nesta pesquisa (Tabela1), porém, se estes estiverem em grandes quantidades é indicativo de lesão tubular aguda (MOEKEL, 2018).

Os cilindros hialinos são constituídos por precipitado proteicos de mucoproteína Tamm-Horsfall e nos casos em que essas proteínas estão associadas a restos celulares formam os cilindros granulosos, que quando envelhecem ou se deterioram, solidificam transformando-se em cilindros céreos (WANGSIRIPAISAN et al., 2001).

Já a cristalúria ocorre pela precipitação em excesso de substâncias na urina provenientes de distúrbios metabólicos, produtos tóxicos, fatores relacionados a hereditariedade e é influenciada pelo $\mathrm{pH}$ da urina. A retenção dos cristais pode culminar na formação de cálculos e ocasional obstrução ureteral, uretral ou renal (DAUDON; FROCHOT, 2015).

É importante ressaltar que pacientes mais propensos a desenvolver cristalúria são aqueles com densidade urinária elevada que possuem concentração alta de substâncias formadoras de cristais ou que tem redução do fluxo urinário. A observação ocasional de cristais na urina, como nesta pesquisa, pode não ter significado clínico pois se tratam de animais saudáveis, sem histórico de urolitíase e sem sinais clínicos relevantes (REINE; LANGSTON, 2005).

Os cães, mesmo dentro dos parâmetros de normalidade, apresentaram em seus sedimentos urinários bacteriúria, cilindrúria e cristalúria sendo estes raros a discretos, o que deve ser acompanhado pelo médico veterinário, pois como foi descrito anteriormente, pode se tratar de um achado acidental sem significância clínica ou ser ocasionalmente o começo de alguma enfermidade que pode culminar em uma lesão renal.

Também não foram observadas diferenças significativas $(p>0,05)$ entre os parâmetros cristais, cilindros, corpúsculos gordurosos, células vesicais e espermatozoides (tabela 1), assim como nos valores de $\mathrm{pH}$, sangue e proteína da tira urinária (figura 2) entre as técnicas avaliadas.

Não houve qualquer diferença nas classificações dos parâmetros: cor, odor e turbidez na análise física da urina entre as técnicas avaliadas. Além disso, na análise química nenhuma amostra mostrou-se positiva para os parâmetros: urobilinogênio, glicose, corpos cetônicos, bilirrubina e nitrito, independente da forma de coleta.

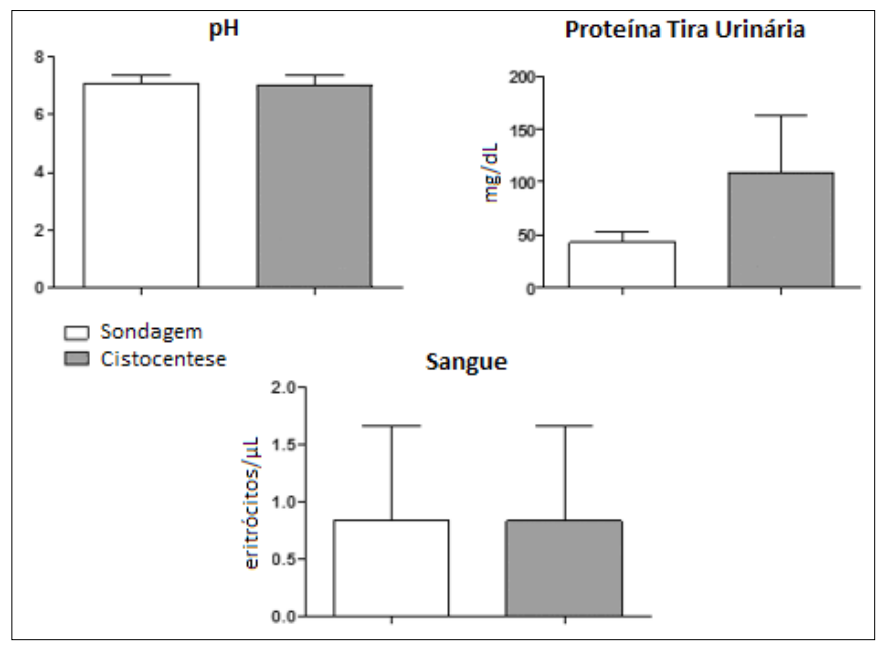

Figura 2 Demonstração gráfica dos valores médios e desvios padrão das variáveis $\mathrm{pH}$, proteína e sangue obtidos pela avaliação da urina por meio da tira reagente para urinálise, nas amostras de cães machos inteiros obtidas por cistocentese e sondagem uretral. Sendo os valores de $p$ encontrados, respectivamente: $p=0,93, p=0,23, p=1,00$

Neste estudo não foi constatada proteinúria evidente em nenhum dos cães de acordo com a classificação da IRIS, somente animais considerados limítrofes, com RPC entre 0,2 e 0,5, assim como não houve diferenças entre os resultados de RPC, proteína urinária, creatinina urinária e microalbuminúria associadas a forma de coleta da amostra (figura 3).

Estes animais limítrofes devem ser acompanhados e realizadas avaliações com no mínimo três repetições seriadas para identificar se há redução, constância ou progressão da RPC. Dependendo dos resultados obtidos pode-se identificar a possibilidade desses animais se tornarem proteinúricos.

Todas amostras apresentaram microabuminúria dentro dos valores de referência (1 a $30 \mathrm{mg} /$ decilitro (dL)) de acordo com Grauer (2005). Esses resultados são equivalentes a traços ou a uma cruz de proteína na fita de urinálise, sendo que os animas possuíam alta densidade urinária. Tais valores de proteína encontrada na tira urinária associados à elevada densidade da urina encontrados nos animais do presente estudo, podem ser aceitos como uma variação da espécie e não evidencia uma enfermidade (STOCKHAM; SCOTT, 2011).

Alguns dos animais do presente estudo apresentaram hematúria identificada por meio da análise química e da análise sedimentoscópica da urina. Como não houve alteração na coloração das amostras de urina, que é verificada na fase física 


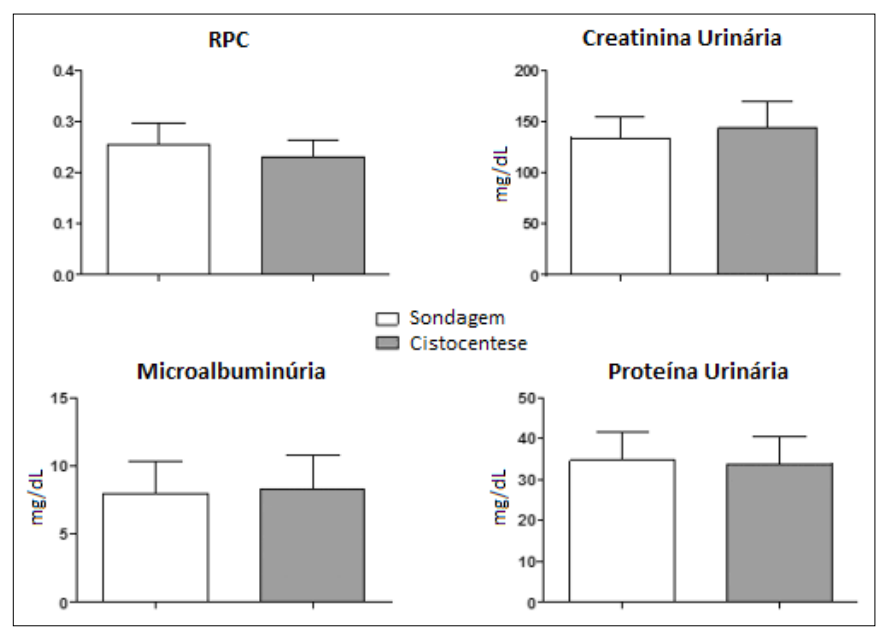

Figura 3 : Demonstração gráfica dos valores médios e desvios padrão das variáveis da relação proteína e creatinina urinária (RPC), proteína urinária, creatinina urinária e microalbuminúria, nas amostras de cães machos inteiros coletadas via cistocentese e sondagem uretral. Sendo os valores de $p$ encontrados, respectivamente: $p=0,63, p=0,93, p=0,78, p=0,92$

da urinálise, a hematúria não interferiu nas concentrações de albumina urinária (VADEN et al, 2004) e consequentemente não foi capaz de alterar os valores das RPC.

Neste estudo, as amostras coletadas por sondagem uretral não obtiveram interferências dos possíveis contaminantes provenientes desta forma de coleta nas dosagens de RPC.

\section{Referências}

BEATRICE, L.; NIZI, F.; CALLEGARI, D.; PALTRINIERI, S.; ZINI, E.; D'IPPOLITO, P.; ZATELLI, A. Comparison of urine protein-tocreatinine ratio in urine samples collected by cystocentesis versus free catch in dogs. Journal of the American Veterinary Medical Association, v.236, n.11, p.1221-1224. 2010.

CHEW, D. J.; DIBARTOLA, S. P.; SCHENCK, P. A. Urologia e Nefrologia do Cão e do Gato. 2 ed. Rio de Janeiro: Elsevier, 2012. 524p.

DAUDON, M.; FROCHOT, V. Crystalluria. Clinical Chemistry and Laboratory Medicine, v. 53, p.1479-1487, 2015.

DIBARTOLA, S. P., CHEW D.J., JACOBS, G. Quantitative urinalysis including 24-hour protein excretion in the dog. Journal of the American Animal Hospital Association, v. 16, n. 4, p. 537$546,1980$.

FORRESTER, S.D. Diagnostic approach to hematuria in dogs and cats Veterinary Clinics of North America: Small Animal Practice, v.34, p.849-866, 2004.

FOSSUM, T. W. Cirurgia de Pequenos Animais. 4 ed. Rio de Janeiro: Elsevier, 2014. 1619p.

GRAUER, G. F. Early detection of renal damage and disease in dogs and cats. Veterinary Clinics of North America: Small Animal Practice, v. 35, p. 581-596, 2005.

International Renal Interest Society - IRIS. IRIS Guidelines (online). 2013a. Disponível em: <http://www.iris-kidney.com/ guidelines/>. Acesso em 10 jun. 2017.

International Renal Interest Society - IRIS. Urine collection. 2013b. Disponível em: <http://www.iris-kidney.com/education/ urine-collection.html>. Acesso em 10 jun. 2017.
O mesmo aconteceu com o estudo de Beatrice et al. (2010) e Vilhena et al. (2015) realizado a partir de amostras coletadas por micção espontânea.

Já, Marynissen et al. (2017) indicaram a micção espontânea como uma boa alternativa de coleta para a avaliação da RPC em animais idosos, devido a facilidade de coleta, podendo muitas vezes ser realizada pelo tutor. De forma oposta, , Dibartola et al. (1980) e a IRIS (2013b) descreveram como recomendável a coleta de urina pelo método de cistocentese para a realização de dosagens de RPC e microalbuminúria, por ser uma punção que promove menor descamação celular e ser minimamente contaminada. Assim,, os resultados obtidos pela cistocentese teriam menos interferências, e seriam mais precisos.

A urinálise com avaliação do sedimento urinário, bem como a realização da RPC e microalbuminuria deveriam ser realizas em todas as amostras, pois nem sempre um animal com alteração renal, ou que venha a se tornar doente renal demonstra sintomas ou sinais clínicos específicos, isso geralmente acontece quando há um agravamento e uma doença renal já instaurada. A realização rotineira destes exames pode resultar em diagnósticos e tratamentos preventivos precoces (CHEW et al., 2012).

\section{Conclusões}

Conclui-se que as técnicas de coleta propostas nesse estudo, não alteraram a urinálise, tampouco a bioquímica urinária, mostrando que as duas técnicas são confiáveis para o diagnóstico de lesão do trato urinário.

International Renal Interest Society - IRIS. Staging of CKD, 2016. Disponível em: <http//www.iriskidney.com/guidelines/en/staging_ ckd.shtml. Acesso em: 07 abr. 2017.

KANEKO, J.J.; HARVEY, J.W.; BRUSS, M.L. Clinical biochemistry of domestic animals. 5 ed. New York: Academic Press, 1997, 932p.

MARYNISSEN, S.J.J.; WILLEMS, A.L.; PAEPE, D.; SMETS, P.M.Y.; PICAVET, P.; DUCHATEAU, L. DAMINET, S. Proteinuria in Apparently Healthy Elderly Dogs: Persistency and Comparison Between Free Catch and Cystocentis. Journal of Veterinary Internal Medicine, v.31, p.93-101, 2017.

MOEKEL, G. Pathologic Perspectives on Acute Tubular Injury Assessment in the Kidney Biopsy. Seminars in Nephrology, v. 38, n.1, p. 21-30, 2018.

REINE, N. J; LANGSTON, C. E. Urinalysis interpretation: how to squeeze out the maximum information from small sample. Journal Clinical Techniques in Small Animal Practice, v. 20, p. 2-10, 2005.

RIZZI, T.E.; VALENCIANO, A.; BOWLES, M.; COWELL, M.; TYLER, R.; DeNICOLLA, D.B. Atlas of Canine and Feline Urinalysis. 1 ed. River Street: Hoboken, 2017. 189p.

STOCKHAM, S. L.; SCOTT, M. A. Fundamentos de patologia clínica veterinária. 2 ed. Rio de Janeiro: Guanabara Koogan, 2011, 744p.

THRALL, M.A.; WEISER, G.; ALLISON, R.; CAMPBELL, T.W. Hematologia e Bioquímica Clínica Veterinária. 2 ed. São Paulo: Roca, 2015, 688p.

VADEN, S. L.; PRESSLER, B. M.; LAPPIN, M. R., JENSEN; W. A. Effects of urinary tract inflammation and sample blood contamination on urine albumin and total protein concentrations in canine urine samples. Veterinary clinical pathology, v. 33, n. 1, p. 14-19, 2004. 
VAP, L.M.; SHROPSHIRE, S.B. Urine Cytology Collection, Film Preparation, and Evaluation. Veterinary Clinics of North America: Small Animal Practice, v.47, p.135-149, 2017.

VILHENA, H. C.; SANTOS, R. R.; SARGO, T. J.; LIMA, T. B.; DIAS, S. S.; PASTORINHO, M. R.; QEUIROGA F. L.; SILVESTRE-FERREIRA, A. C. Urine protein-to-creatinine concentration ratio in samples collected by means of cystocentesis versus manual compression in cats. Journal of the American Veterinary Medical Association, v.246, n.8, p.862-867, 2015.

WAKI, M. F.; MARTORELLI, C. R.; ERDMANN MOSKO, P.; KOGIKA, M. M. Classificação em estágios da doença renal crônica em cães e gatos: abordagem clínica, laboratorial e terapêutica. Ciência rural, v.40, n.10, p.2226-2234, 2010.

WANGSIRIPAISAN, A.; GENGARO, P.E.; EDELSTEIN, L.C.; SCHRIER, R.W. Role of polymeric Tamm-Horsfall protein in cast formation: Oligosaccharide and tubular fluid ions. Kidney International, v.59, n.3, p.932-940, 2001.
WEESE, J. S.; BLONDEAU, J. M.; BOOTHE, D.; BREITSCHWERDT, E. B.; GUARDABASSI, L.; HILLIER, A.; LLOYD, D. H; PAPICH, M. G.; RANKIN, S. C.; TURNIDGE J. D.; SYKES, J. E. Antimicrobial use guidelines for treatment of urinary tract disease in dogs and cats: antimicrobial guidelines working group of the international society for companion animal infectious diseases. Veterinary medicine international, v. 2011, p.1-9, 2011.

WHITTEMORE, J. C.; MIYOSHI, Z.; JENSEN, W. A.; RADECKI, S. V.; LAPPIN, M. R. Association of microalbuminuria and the urine albumin-to-creatinine ratio with systemic disease in cats. Journal of the American Veterinary Medical Association, v.230, n.8, p.1165-1169. 2007. 